\title{
PRODUÇÃO DE VACINAS VIRAIS PARTE I: engenharia de bioprocessos
}

\author{
Guilherme Mateus BOUSADA ${ }^{1}$ \\ Erlon Lopes PEREIRA ${ }^{2}$
}

\begin{abstract}
${ }^{1}$ Setor de Engenharia Química. Departamento de Química. Universidade Federal de Viçosa. Campus Viçosa-MG. guilherme.bousada@ufv.br.

${ }^{2}$ Setor de Engenharia Química. Departamento de Química. Universidade Federal de Viçosa. Campus Viçosa-MG. erlonlopes@gmail.com
\end{abstract}

Recebido em: 29/08/2016 - Aprovado em: 10/03/2017 - Disponibilizado em: 01/07/2017

\section{RESUMO}

As vacinas são uma das maiores conquistas da humanidade em termos de diminuição das doenças. O correto entendimento de sua produção, a partir não só dos conhecimentos biológicos, mas também em termos de engenharia, é de fundamental importância para que os avanços já adquiridos possam ir cada vez mais longe. A produção de vacinas torna-se, assim, um importante nicho de pesquisa para os engenheiros, de modo especial na produção de vacinas virais, destacadas no presente artigo, em que o cultivo de células animais deve estar alinhado com as questões de biossegurança e bioética. Como estudo de caso é apresentada a produção da vacina contra o influenza no Instituto Butantan, no Brasil. A segunda parte do artigo discute, sob a perspectiva da bioética personalista ontologicamente fundada, sobre a eticidade do uso de linhagens celulares derivadas de abortos, tais como a MRC-5, WI-38, PER.C6 e HEK293, na produção de algumas vacinas.

PALAVRAS-CHAVE: Vacinas virais. Engenharia de bioprocessos. Escalonamento. Biossegurança. Bioética.

\section{ABSTRACT}

Vaccines are one of the most important achievements of humankind in terms of protection against diseases. The understanding of their production, considering not only biological issues, but also the engineering perspective, is of core importance for the continuous improvement in this field. The Bioprocess Engineering aproach conveys an important area for engineer survey, particularly for virus vaccines, described in more detail in this article, where animal cells cultivation is deeply related with economics, bio-safety and bioethical issues.As a study case, this article also presents the influenza vaccine production by Butantan Institute, in Brazil. The second part of this article discusses, under ontologically founded personalist bioethics perspective, about the use of cell cultures derived from abortions, such as MRC-5, WI-38, PER.C6 e HEK293, in the production of some vaccines.

KEYWORDS: Viral vaccines.Bioprocess engineering.Scale-up.Bio-safety.Bioethics.

\section{IINTRODUÇÃO}

A história das vacinas remonta aos trabalhos pioneiros de Jenner (1749-1823), no final do século XVIII, quando ele utilizou material obtido de lesões de pele de animais infectados pela varíola bovina a fim de promover a imunização. Tal atitude deveu-se à observação que os ordenhadores que tinham contato com os bovinos acometidos pela doença desenvolviam formas mais brandas da enfermidade que se apresentava como epidemia na Europa (HISS, 2001; SCHATZMAYR, 2003). Devido aos primeiros estudos terem sido realizados com bovinos deu-se o nome de vacina, que deriva do latim vacca(vaca), ao produto. Embora Jenner tenha publicado seu estudo no século XVIII, Hiss (2001) e Schatzmayr (2003) 
descrevem que na China no século VI pessoas saudáveis eram expostas a secreções provenientes de pessoas que haviam sido infectadas por essa doença, sendo essa possivelmente a primeira tentativa de vacinação contra a varíola.

De acordo com Hiss (2001) nem mesmo os antibióticos foram tão eficazes quanto as vacinas na diminuição da mortalidade. Dado disponibilizado pelo Boletim da Organização Mundial da Saúde (ANDREet al., 2008) mostra que nenhum outro avanço no campo do combate às doenças infecciosas teve tanto impacto quanto as vacinas, exceto a utilização da água potável, sendo confirmado pela empresa Sanofi Pasteur (2012a).

Independentemente do agente causador da doença, as vacinas têm como principal objetivo estimular as defesas imunológicas do organismo (SANOFI PASTEUR, 2012a). Valendo-se das próprias bactérias ou vírus causadores das doenças, ou mesmo de fragmentos retirados deles, é possível obter proteção contra doenças de modo eficaz e duradouro (SANOFI PASTEUR, 2012a). De acordo com o Centers for Disease Controland Prevention (2015), do U.S. Department of Health and Human Services (Departamento de Saúde e Serviços Humanos dos EUA), existem atualmente vacinas que protegem contra mais de 20 doenças humanas.

Segundo Hiss (2001), a vacinação controlou nove principais doenças em algumas partes do mundo,desde seu surgimento até os dias atuais: varíola, difteria, tétano, febre amarela, coqueluche, poliomielite, sarampo, caxumba e rubéola. A varíola, segundo o autor, foi considerada erradicada pela Organização Mundial da Saúde (OMS) em 9 de dezembro de 1979. Esse sucesso tem crescido ainda mais com o rápido progresso nos campos da imunologia e da biologia molecular, tornando possível o desenvolvimento de novas técnicas de imunização (SCHATZMAYR, 2003).

A primeira parte do artigo teve como objetivo contribuir para o entendimento da produção das vacinas sob a perspectiva da Engenharia de Bioprocessos descrevendo os aspectos biotecnológicos utilizados para a produção de vacinas virais. Como estudo de caso foi apresentada ainda a produção da vacina contra a influenza sazonal realizada no Instituto Butantan, no Brasil, sendo consideradas ainda perspectivas de mudanças para essa forma de produção. Na segunda parte este trabalho vem apresentar uma reflexão, sob a perspectiva da bioética personalista ontologicamente fundada, sobre o uso de linhagens celulares oriundas de fetos abortados, tais como a MRC-5, WI-38, PER.C6 e HEK293 na produção de algumas vacinas.

\section{O PROCESSO DE IMUNIZAÇÃO}

Para o melhor entendimento a respeito 
do funcionamento das vacinas, Schatzmayr (2003) salienta a necessidade de se levar em conta os mecanismos de resposta imunológica dos organismos. Segundo Hiss (2001), o princípio básico de ação das vacinas dá-se pela exposição do organismo aos antígenos, que são substâncias presentes nos micro-organismos e que estimulam a produção de anticorpos no hospedeiro. Unindo sua exposição à de Schatzmayr (2003), entende-se que a introdução do antígeno no organismo a ser imunizado induz uma resposta imunológica sem que seja contraída a doença. Tal processo pode ser denominado imunização ativa artificialmente adquirida. Essa imunização ocorre devido à formação de células de memória, que após terem tido contato com o antígeno são capazes de ativar, mesmo após longo tempo, as células específicas de defesa.

Segundo Hiss (2001) outras formas de imunização seriam as imunizações ativa (IA) e a passiva (IP) naturalmente adquiridas e a imunização passiva artificialmente adquirida (IPA). De acordo com os autor a IA ocorre quando o contato com o antígeno é realizado através de feridas ou outras vias de "contaminação", como ocorreu no caso observado por Jenner. Já a IP ocorre quando há passagem de anticorpos da mãe para a criança em formação. A IPA, por sua vez, ocorre no caso da administração de soros.

\section{PRINCIPAIS TIPOS DE VACINAS}

Segundo JosefsbergeBuckland (2012), as vacinas podem ter origem viral ou bacteriana, contendo os organismos inteiros, macromoléculas específicas purificadas, vetores recombinantes, peptídeos sintéticos ou DNA. O Quadro 1 apresenta algumas vacinas agrupadas segundo seus componentes principais.

Quadro 1- Classificação de vacinas para uso humano.

\begin{tabular}{|l|l|}
\hline \multicolumn{1}{|c|}{ Classificação } & \multicolumn{1}{c|}{ Exemplos de vacinas licenciadas } \\
\hline Vírus atenuado & $\begin{array}{l}\text { Varíola, poliomielite, sarampo, caxumba, rubéola, varicela, } \\
\text { rotavírus, herpes zóster, gripe e febre amarela. }\end{array}$ \\
\hline Vírus inativado encefalite japonesa,hepatite A, \\
\hline Bactéria atenuada & $\begin{array}{l}\text { Pólio inativada , } \\
\text { Influenza(sazonal e pandêmica ) e raiva. }\end{array}$ \\
\hline Bactéria inativada & Tuberculose e febre tifóide. \\
\hline Proteína purificada & Coqueluche. \\
\hline Toxóide (proteína) purificado & Coqueluche acelular. \\
\hline
\end{tabular}




\begin{tabular}{|l|l|}
\hline Partículas purificadas que imitam vírus (VLPs) & Hepatite B e vírus do papiloma humano. \\
\hline Polissacarídeos purificados & Pneumocócica para adultos e febre tifóide. \\
\hline $\begin{array}{l}\text { Polissacarídeo conjugado } \\
\text { à proteína carreadora }\end{array}$ & $\begin{array}{l}\text { Pneumocócica para crianças, tipo haemophilus B e meningite } \\
\text { bacteriana. }\end{array}$ \\
\hline DNA plasmídico & Em desenvolvimento. \\
\hline Adenovírus carreadorde DNA & Em desenvolvimento. \\
\hline
\end{tabular}

FONTE: Josefsberge Buckland (2012).

Tendo em vista o amplo espectro de classificações das vacinas indicados no Quadro 1, o presente artigo irá limitar-se às vacinas virais. $\mathrm{O}$ artigo de JosefsbergeBuckland (2012) pode ser consultado para maior detalhamento de outros tipos de vacinas.

\section{DESAFIOS PARA A PRODUÇÃO EM}

\section{LARGA ESCALA}

Segundo Schatzmayr(2003), o principal problema relativo à produção das vacinas seria a baixa participação dessas no mercado mundial, o que diminuiria o interesse das indústrias farmacêuticas em sua produção. Essa informação foi confirmada por recente notícia divulgada pela BCC Brasil, em que se reconhece a negligência do setor farmacêutico diante do ramo de vacinas, que representa apenas uma pequena parcela de lucros (DUARTE, 2016).

Buckland (2005), por sua vez, afirmou que apenas as empresas farmacêuticas Merck \&Co.,Inc, GlaxoSmithKline, Wyeth e Sanofi Pasteur possuíam o necessário para produzir novas vacinas. Isso demonstra concentração do capital intelectual e da tecnologia nesse setor. Todavia, o autor concluiu que o cenário apresentava perspectivas de mudança. Hiss (2001), Schatzmayr (2003) e Sthephens (2014) descreveram que além desses problemas mencionados existiam outros que afetavam a produção em larga escala como:

- A grande maioria dos profissionais trabalhando nesse campo é composta por cientistas(biólogos, médicos e farmacêuticos), faltando profissionais com conhecimentos de Engenharia.

- Dificuldades de integração entre a academia e a indústria.

- Dificuldades inerentes ao processo, tais como o uso de meios complexos, necessidade de assepsia estrita.

- As condições do meio favorecem o crescimento de um amplo espectro de micro-organismos (temperaturas ao redor de $37^{\circ} \mathrm{C}$ e $\left.\mathrm{pH} 7,5\right)$.

- Necessidade de grande atenção quanto ao risco de infecção dos operadores. 
- Os antígenos não são o produto metabólico principal.

- Os produtos tendem a ser lábeis.

- Existe perigo de responsabilização da indústria devido a efeitos adversos inesperados.

- A alta regulação e burocracia no desenvolvimento das vacinas encarece o processo.

- Os países que seriam virtualmente os maiores consumidores do produto são os que possuem o menor poder de compra.

Em relação às dificuldades de integração entre a academia e a indústria, apresentada entre os pontos acima, Alisson e Tranter (2010) discutiram sobre como os profissionais da academia que pesquisam nesse campo geralmente desconhecem as dificuldades econômicas e de regularização de um processo biofarmacêutico em larga escala. Segundo os autores os trabalhos de bancada exigem quantidades de material pequenas e têm como objetivo principal a obtenção de produtos com alta pureza, sendo muitas vezes desconsiderado o fato de que alguns métodos empregados laboratorialmente são inviáveis para maiores produções. O Quadro 2 mostra processos alternativos para o escalonamento de um processo.

Uma sugestão apresentada por Alisson e Tranter (2010) seria a de que os pesquisadores pensassem previamente sobre como os projetos de pesquisa seriam implementados a nível industrial. Essa recomendação mostra claramente a necessidade de maior integração entre a academia e a indústria a fim de que os projetos de pesquisa não fiquem apenas no papel.

Quadro 2- Métodos alternativos para escalonamento.

\begin{tabular}{|l|l|l|}
\hline \multicolumn{1}{|c|}{ Função } & \multicolumn{1}{|c|}{ Método de Pesquisa } & \multicolumn{1}{c|}{ Alternativas para scale-up } \\
\hline Iniciação da expressão & Adição de indutor químico. & $\begin{array}{l}\text { Expressão intrínseca, indução por mudança } \\
\text { fisiológica. }\end{array}$ \\
\hline Crescimento celular & Cultura em erlenmeyrs agitados. & $\begin{array}{l}\text { Fermentação por batelada ou batelada } \\
\text { alimentada. }\end{array}$ \\
\hline Rompimento celular & Sonificação. & $\begin{array}{l}\text { Homogeneizadores a alta pressão, moinhos } \\
\text { de esferas, lise química. }\end{array}$ \\
\hline $\begin{array}{l}\text { Decrescimento da atividade } \\
\text { proteolítica }\end{array}$ & Uso de inibidores de proteases. \\
\hline $\begin{array}{l}\text { Remoção do DNA do } \\
\text { hospedeiro }\end{array}$ & Uso de nucleases. & $\begin{array}{l}\text { Uso de linhagens deficientes na produção de } \\
\text { proteases. }\end{array}$ \\
\hline $\begin{array}{l}\text { Remoção de particulados } \\
\text { usando membranas. }\end{array}$ \\
\hline Centrifugação em batelada. & $\begin{array}{l}\text { Centrifugação por fluxo contínuo, filtração } \\
\text { por fluxo tangencial, cromatografia de leito } \\
\text { expandido. }\end{array}$ \\
\hline Troca de tampão & Polimixina. \\
\hline
\end{tabular}

FONTE: Alisson e Tranter (2010). 
Apesar das dificuldades apresentadas por Hiss (2001), Schatzmayr (2003), Buckland (2005) e Sthephens (2014), Hiss (2001) afirmou que a produção de vacinas em escala piloto com reatores pode ser suficiente para o atendimento da demanda, diferentemente de outros processos biológicos, que exigem um maior volume para uma única batelada. Os valores de volumes de cultura utilizados para o preparo de uma dose humana total de vacina estão apresentados na Tabela 1.

Tabela 1: Valores aproximados de volumes de cultura para o preparo de uma dose humana total (dht*) de algumas vacinas bacterianas e virais.

\begin{tabular}{lcc}
\hline \multicolumn{1}{c}{ Tipo de vacina } & Inoculação por dht & mL de cultura por dht \\
\hline Pertussis & 3 & 1,0 \\
Difteria & 3 & 0,3 \\
Tétano & 3 & 0,3 \\
a-estafilocócica & 2 & 0,5 \\
Cólera (via parental) & 2 & 0,2 \\
Cólera (via oral) & 2 & 2,0 \\
Tifo (via parental) & 2 & 0,02 \\
Tifo (via oral) & 2 & 2,0 \\
BCG & 1 & 0,02 a 0,1 \\
Pólio (inativada) & 3 & 6 \\
Pólio (atenuada) & 3 & 0,1 \\
Varíola & 1 & 0,03 \\
Sarampo (inativada) & 3 & 1,0 \\
Sarampo (atenuada) & 1 & 0,003 \\
Rubéola (atenuada) & 1 & 0,1 \\
\hline
\end{tabular}
FONTE: Hiss (2001).

*Dose humana total é o número de vezes em que se deve administrar a vacina para adquirir a imunidade pretendida.

A Tabela 1 indica claramente os altos rendimentos conseguidos na produção das doses vacinais, já na época de sua elaboração. Como exemplificação, Hiss (2001) sugere que 25 bateladas anuais de $2000 \mathrm{~L}$ em um único biorreator de $3300 \mathrm{~L}$ seriam suficientes para produzir 50 milhões de doses vacinais contra a pertussis.

Os avanços tecnológicos também favorecem a implementação industrial. Um exemplo disso são as vacinas virais, quede acordo com Hiss (2001) e Schatzmayr (2003) seriam difíceis de serem produzidas em larga escala devido às condições especiais de cultivo, como o uso de peles de bezerro e ovos de galinha. Tais dificuldades foram superadas pelo cultivo submerso, que permite um maior controle (HISS, 2001).

Dados da OMS (2016), no entanto, indicam que atualmente cerca de $80 \%$ do mercado mundial de vacinas advém da produção de cinco grandes multinacionais, atestando que o mercado permanece restrito. 


\section{PRODUÇÃO DE VACINAS VIRAIS}

\subsection{Classificação das Vacinas Virais}

De acordo com Josefsberg e Buckland(2012), as primeiras vacinas produzidas foram as virais e as bacterianas. Para o segundo caso, empregam-se processos fermentativos nos quais as próprias bactérias são cultivadas (HISS, 2001). As vacinas virais, por outro lado, exigem o uso de células hospedeiras a fim de que os vírus possam se multiplicar, pois são parasitas celulares obrigatórios que necessitam do maquinário da célula hospedeira para produzir suas proteínas (HISS, 2001).

Schatzmayr (2003) classifica as vacinas virais em dois grupos básicos: as vivas e as mortas. As primeiras conteriam vírus ativos, enquanto nas segundas os vírus teriam sido inativados por métodos físicos ou químicos. No caso das vacinas mortas, a inativação dos vírus dá-se com o uso de formol ou detergentes, como no caso da gripe. $\mathrm{O}$ autor apresenta como vantagemdesse tipo de vacina a maior segurança para o vacinado. Como desvantagem apresenta o fato de que esse tipo de vacina pode produzir uma resposta imunológica menos eficiente e duradoura em comparação às vacinas vivas. Pode-se concluir que isso significaria um custo mais alto, pois quanto maior o número de doses que deverão ser administradas, menor será o número de vacinados para a mesma quantidade de produto.

Segundo Schatzmayr (2003) as vacinas vivas apresentam vantagens em relação às mortas. Elas possuem menor custo e facilidade de produção em grande escala, o que pode ser exemplificado com os casos da tentativa de erradicação da varíola e da poliomielite. Além disso, Schatzmayr (2003) e Strugnellet al. (2011) afirmaram que o sistema imunológico responde melhor às vacinas vivas, uma vez que simulam a infecção natural, garantindo também uma proteção mais duradoura. Todavia, os mesmos autores apresentaram como desvantagem a dificuldade de estocagem, devido à maior possibilidade de deterioração, sendo necessária a refrigeração para os casos em que não é possível a liofilização. Outra desvantagem é o risco, ainda que pequeno, da amostra readquirir virulência.

Schatzmayr (2003) descreveu que uma das formas de obtenção das vacinas vivas consistiria em fazer com que os vírus passem por células de variados hospedeiros, em diferentes condições de temperatura, até que surjam ao acaso mutantes menos virulentos. Segundo o mesmo autor, devido à aleatoriedade do processo, às vezes não é possível obter resultados equivalentes, mesmo repetindo-se as condições anteriores. A vacina contra a febre amarela, a $17 \mathrm{D}$, foi obtida a 
partir desse método (FRIERSON, 2010).

Outras técnicas mais sofisticadas para a obtenção dos vírus atenuados são as técnicas de biologia molecular. Schatzmayr (2003) destaca as técnicas de deleção, inserção e quimeras virais. $\mathrm{Na}$ técnica de deleção são retirados segmentos genômicos do DNA viral, objetivando produzir uma menor virulência sem, no entanto, impedir a formação do antígeno. Na técnica de inserção são inseridos fragmentos genômicos no DNA viral fazendo com que sua replicação no hospedeiro seja limitada, semimpedir a formação dos anticorpos. A desvantagem dessa técnica, segundo o autor, é a dificuldade de prever as consequências das inserções para o organismo hospedeiro e para o preparo geral das vacinas. $\mathrm{Na}$ técnica com produção de quimeras virais as mesmas são obtidas pela conexão de vários fragmentos virais distintos.

O Quadro 3 resume, de maneira comparativa, algumas características das vacinas vivas e mortas.

Quadro 3-Características de vacinas vivas e mortas.

\begin{tabular}{|l|l|}
\hline \multicolumn{1}{|c|}{ Vacinas vivas } & \multicolumn{1}{|c|}{ Vacinas mortas } \\
\hline $\begin{array}{l}\text { Exemplos: pólio oral, sarampo/caxumba/ rubéola, } \\
\text { varicellazóster, algumas para gripe. }\end{array}$ & Exemplos: pólio inativa, hepatite A. \\
\hline $\begin{array}{l}\text { Simulam melhor uma infecção natural, favorecendo a } \\
\text { resposta imunológica, mas podem reter mais fatores de } \\
\text { evasão imune. }\end{array}$ & $\begin{array}{l}\text { Geralmente requer o uso de adjuvantes devido à } \\
\text { menor resposta imunológica. }\end{array}$ \\
\hline Resposta imunológica obtida com apenas 1-2 doses. & Geralmente necessita de doses múltiplas. \\
\hline $\begin{array}{l}\text { Resposta imunológica longa e persistente. } \\
\text { Pode induzir alguns sintomas da doença de maneira } \\
\text { branda. }\end{array}$ & $\begin{array}{l}\text { Podem ser necessárias doses de reforço para manter } \\
\text { imunidade a longo prazo. }\end{array}$ \\
\hline $\begin{array}{l}\text { Reversão à virulência rara, mas possível. } \\
\text { Incompatibilidade com pacientes imunodeficientes. }\end{array}$ & É não infecciosa, não havendo risco de reversão. \\
\hline $\begin{array}{l}\text { Possibilidade de interferência imunológica quando com } \\
\text { outras vacinas vivas. }\end{array}$ & Há baixorisco de interferência imunológica. \\
\hline $\begin{array}{l}\text { Menos estável com o tempo. Sensível ao calor. } \\
\text { Resposta afetada se tiver havido administração recente de } \\
\text { sangue ou derivados ou a presença de anticorpos } \\
\text { maternos na criança. }\end{array}$ & $\begin{array}{l}\text { Relativamente estável com o decorrer do tempo e mais } \\
\text { resistente a mudanças na temperatura de refrigeração. }\end{array}$ \\
\hline
\end{tabular}

FONTE: STRUGNELL et al, 2011.

As características desses tipos de vacinas apresentados no Quadro 3 devem ser levadas em consideração ao se pensar em fazer uma implementação em escala industrial.

\subsection{Culturas Celulares para a Produção de Vacinas Virais}

$$
\text { Josefsberg e Buckland }
$$

descreveram que o primeiro cultivo de uma 
vacina viral foi em 1949, por Enders, utilizando para isso células humanas não-neurais. Esse fato foi relevante porque o poliovírus, cultivado por Enders, era considerado estritamente neurotrópico (NORRBY, 2007). Segundo os autores, existem dois tipos de culturas celulares: aquelas em que as células são extraídas diretamente de tecidos e órgãos animais, e aquelas em que são utilizadas linhagens celulares de células diplóides modificadas a fim de se reproduzirem indefinidamente. Além disso, ressaltaram o tempo de vida limitado do primeiro tipo de cultivo celular, além de possuir a desvantagem de serem necessariamente dependentes de suporte. Aubritet al. (2015), por sua vez, descrevem também a existência de células diplóides de linhagem não-contínua que não foram descritos por Josefsberg e Buckland (2012). Os Quadros de 4 a 6 mostram algumas linhagens celulares com as respectivas vacinas para uso humano.

Quadro 4- Substrato celular geralmente usado para produção de vacinas humanas utilizando células primárias.

\begin{tabular}{|c|c|c|c|c|}
\hline $\begin{array}{l}\text { Linhage } \\
\text { m } \\
\text { Celular }\end{array}$ & $\begin{array}{l}\text { Tipo de } \\
\text { célula e } \\
\text { origem }\end{array}$ & Susceptibilidade viral & $\begin{array}{c}\text { Em } \\
\text { desenvolviment } \\
\text { o }\end{array}$ & das \\
\hline $\begin{array}{l}\text { CEF } \\
\text { (Chicken } \\
\text { Embryofi } \\
\text { broblast) }\end{array}$ & $\begin{array}{l}\text { Fibroblastos } \\
\text { de embrião } \\
\text { de galinha. }\end{array}$ & $\begin{array}{lr}\text { Febre } & \text { amarela, } \\
\text { raiva,encefalite } & \\
\text { transmitida } & \text { por } \\
\text { carrapatos, } & \text { sarampo, } \\
\text { caxumba. } & \end{array}$ & $\begin{array}{l}\text { Vacinasbaseadas } \\
\text { novírus Vaccinia } \\
\text { Ankara } \\
\text { modificado, } \\
\text { HIV, febre Q. }\end{array}$ & $\begin{array}{l}\text { Raiva } \text { (Rabipur }^{\circledR} \text { ), encefalite } \\
\text { transmitida por carrapatos (FSME - } \\
\text { Immun }^{\circledR}, \quad \text { Encepur }^{\circledR} \text { ), sarampo } \\
\left(\text { Attenuvax }{ }^{\circledR} \text { ), caxumba }\right. \\
\left(\text { Mumpsvax }{ }^{\circledR}\right) .\end{array}$ \\
\hline
\end{tabular}

FONTE: Aubritet al. (2015).

Quadro 5- Substratos celulares geralmente usados para produção de vacinas humanas utilizando linhagem de células diplóides.

\begin{tabular}{|c|c|c|c|c|}
\hline $\begin{array}{l}\text { Linhage } \\
\text { m } \\
\text { Celular }\end{array}$ & $\begin{array}{l}\text { Tipo de } \\
\text { célula e } \\
\text { origem }\end{array}$ & Susceptibilidade viral & $\begin{array}{c}\text { Em } \\
\text { desenvolviment } \\
\text { o }\end{array}$ & Vacinas comercializadas \\
\hline $\begin{array}{l}\text { MRC5 } \\
\text { (Medical } \\
\text { Research } \\
\text { Council) } \\
\end{array}$ & $\begin{array}{l}\text { Pulmão } \\
\text { embrionário } \\
\text { humano. }\end{array}$ & $\begin{array}{l}\text { Varicela zóster, poliovírus, } \\
\text { raiva, hepatite A. }\end{array}$ & Raiva. & $\begin{array}{l}\text { Vírus varicela zóster(Varilrix }{ }^{\circledR} \text {, } \\
\left.\text { Biopox }^{\circledR} \text {, ProQuad }{ }^{\circledR}\right) \text {, poliovírus } \\
\left.\left(\text { Poliovax }^{\circledR}\right) \text {, raiva } \text { Imovax }^{\circledR}\right) \text {, } \\
\text { hepatite A }\left(\text { VAQTA }^{\circledR}\right) .\end{array}$ \\
\hline $\begin{array}{l}\text { WI-38 } \\
\text { (WistarIn } \\
\text { stitute) }\end{array}$ & $\begin{array}{l}\text { Pulmão } \\
\text { embrionário } \\
\text { humano. }\end{array}$ & Rubéola, adenovírus. & - & $\begin{array}{l}\text { Rubéola (Meruvax }{ }^{\circledR} \text { II), adenovirus } \\
\text { (Adenovirus Tipo } 4 \text { e Tipo } 7 \\
\text { Vaccine, Live, Oral }{ }^{\circledR} \text { ). }\end{array}$ \\
\hline
\end{tabular}

FONTE: Aubritet al. (2015). 
Quadro 6- Substratos celulares em estudo para produção de vacinas humanas utilizando linhagens celulares contínuas

\begin{tabular}{|c|c|c|c|c|c|}
\hline 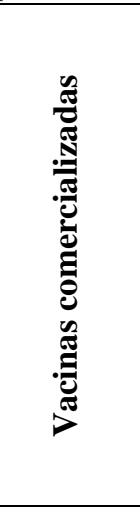 & 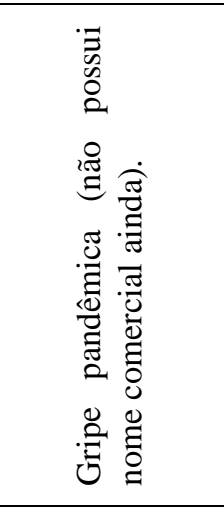 & 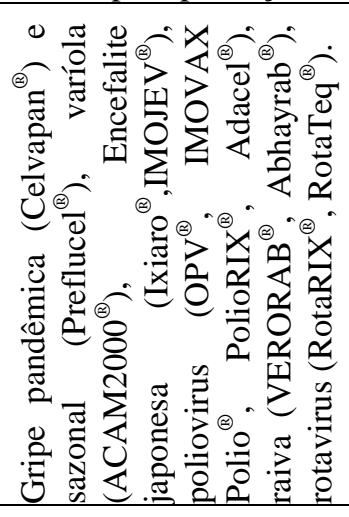 & 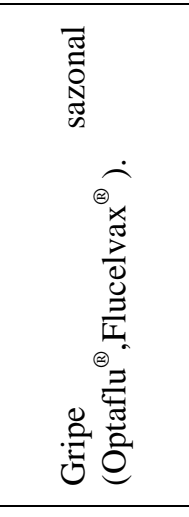 & 1 & 1 \\
\hline 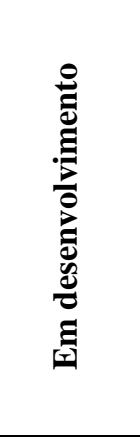 & 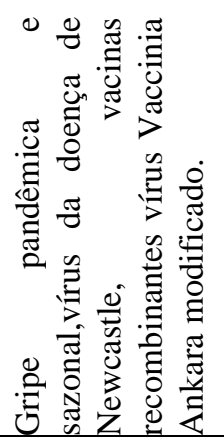 & 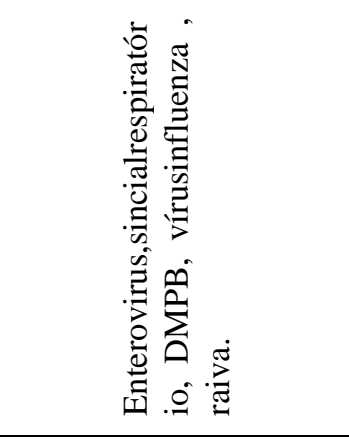 & 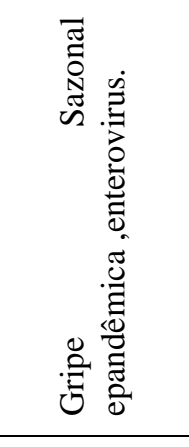 & 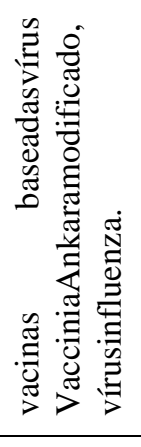 & 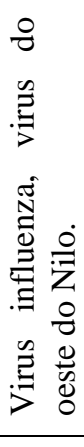 \\
\hline 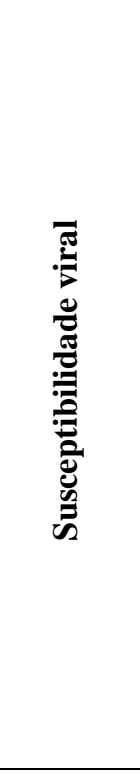 & 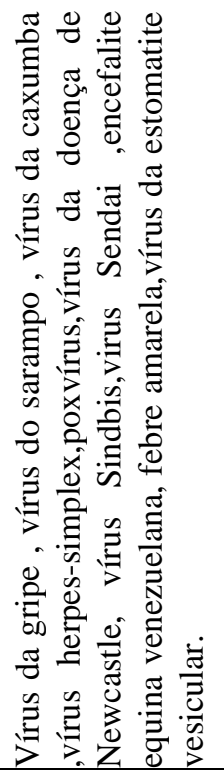 & 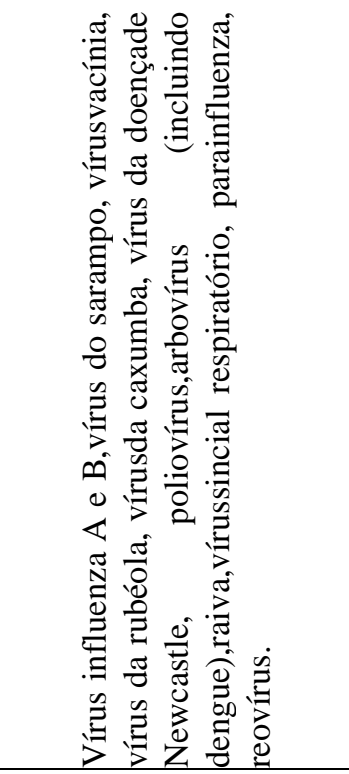 & 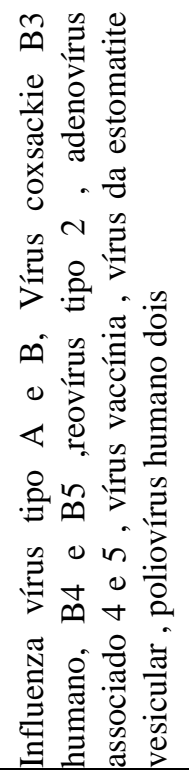 & 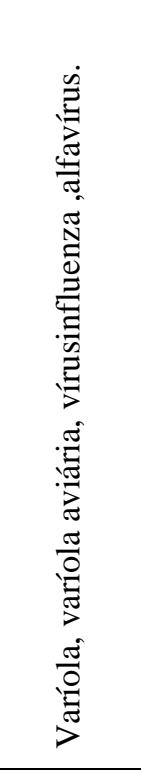 & 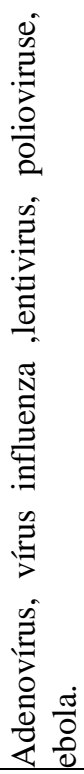 \\
\hline 吾 & 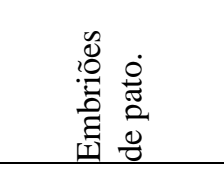 & 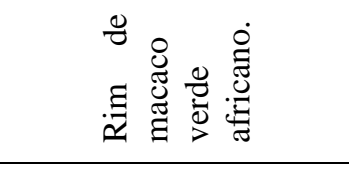 & 古晜 & 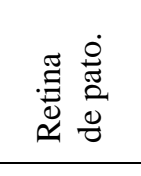 & 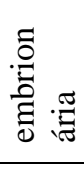 \\
\hline 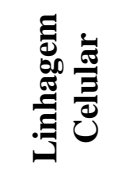 & 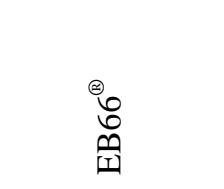 & $>$ & $\begin{array}{l}\text { Ũ } \\
\hat{\Sigma}\end{array}$ & 焉 & $\begin{array}{l}\stackrel{\ominus}{0} \\
0 \\
\frac{\alpha}{10} \\
\frac{1}{2}\end{array}$ \\
\hline
\end{tabular}

FONTE: Aubritet al. (2015). 
Josefsberg e Buckland (2012) reportaram que em 1962 a linhagem Vero, extraída a partir dos rins do macaco verde africano,foi a primeira linhagem de células de mamíferos (Quadro 3). Pailletet al. (2009) indicaram o uso dessa linhagem celular na produção de vacinas contra a raiva, poliomielite, enterovirus 71 e vírus Hantaan. Os autores atestaram ainda arecomendação da Organização Mundial de Saúde para o uso dessa linhagem celular na produção de vacinas para uso humano. Josefsberg e Buckland (2012) confirmaram a amplitude da regularização dessa linhagem celular para a produção de vacinas para uso humano. O Quadro 7 mostra algumas vacinas licenciadas com essa linhagem celular, subdivididas em vacinas vivas e mortas.

Quadro 7- Vacinas licenciadas produzidas a partir da linhagem Vero.

\begin{tabular}{|c|c|}
\hline Tipo de vacina & Exemplos \\
\hline & ACAM20001 (Sanofi Pasteur, Lyon, França), contra a varíola; Rotateq1 (Merck, \\
Vacinas Vivas & WhitehouseStation, Nova Jersey), contra o rotavírus e Rotarix1 (GSK, Brentford, \\
& Middlesex, Reino Unido), também contra o rotavírus. \\
\hline & H5N1Preflucel1 (Baxter, Deerfield, Illinois), pandêmica contra a gripe; Ixiaro1 (Intercell, \\
Vacinas Mortas & Viena, Áustria), contra encefalite japonesa. \\
\hline
\end{tabular}

FONTE: Josefsberg e Buckland (2012).

Schatzmayr (2003) alertou para a necessidade de se eliminar os fatores oncogênicos ao serem utilizadas células de mamíferos para a multiplicação dos vírus. No entanto, de acordo com o autor, a utilização dessas células traria como vantagem a maior similaridade das proteínas virais que são produzidas com aquelas encontradas nas doenças humanas. Segundo Schatzmayr (2003), Kreuzer e Massey (2005) outra alternativa para a produção de proteínas antigênicas seria o uso de células vegetais. $\mathrm{O}$ primeiro autor apresentou resultados de pesquisas referentes à produção de proteínas da doença hemorrágica do coelho e do vírus da hepatite $\mathrm{B}$.

Rappuoli (2006) apresentou algumas características desejáveis para a linhagem celular a ser escolhida na replicação dos vírus, tomando como base os vírus influenza. Seguindo sua linha de raciocínio, pode-se concluir que a linhagem celular a ser escolhida deve, preferencialmente, permitir a replicação dos vírus em grandes quantidades e possuir uma resposta rápida e eficiente nessa replicação, ser adequada para licenciamento nos órgãos responsáveis, permitir a remoção de DNA residual no produto final, assim como das próprias células e de fatores oncogênicos. Deve ainda poder ser usada para diferentes tipos de vírus e crescer em um meio quimicamente definido, evitando aqueles que contêm componentes derivados de animais e, portanto, apresentam flutuações na 
composição. Essa vantagem também viria da menor possibilidade de contaminação quando comparado aos meios com componentes de origem animal (como o soro fetal bovino (AUBRITet al.,2015)). Essa opinião é compartilhada por Astleyet al. (2007) e Aubrit et al. (2015). O segundo autor afirmou, ainda, que nenhuma linhagem celular, nem mesmo as projetadas, é capaz de preencher todos os critérios para todas as vacinas virais.

\section{ENGENHARIA DE BIOPROCESSOS NA PRODUÇÃO DE VACINAS}

\subsection{Operações Unitárias}

Início do cultivo, análise e purificação: Dentre as dificuldades já apresentadas para a implementação em larga escala da produção de vacinas virais destaca-se a biossegurança. As empresas Sanofi Pasteur (2012 a) e a Boehringer Ingelheim Vetmedica (2015) indicaram em seus processos a necessidade de que sejam tomadas precauções constantes para que todo o ambiente esteja estéril, assim como os equipamentos e o meio de cultivo, evitando a contaminação tanto do produto como dos operadores. Segundo a empresa Sanofi Pasteur (2012 a) a preocupação com a segurança dos operadores e com a qualidade do produto final é tanta quepode-se empregar até mais de $70 \%$ do tempo gasto na produção das vacinas realizando-se testes e controle. Algumas vacinas, por exemplo, poderiam exigir a execução de mais de 50 testes durante sua produção, segundo a empresa.

A empresa Sanofi Pasteur (2012b) descreveu o início da produção com a multiplicação dos vírus nas células hospedeiras. Sabe-se, no entanto, que essa etapa ocorre após o crescimento celular. Como já mencionado, a partir de um pequeno volume de cultivo é possível produzir vírus em uma quantidade suficiente paraproduzir muitas doses de vacina. As condições do meio são específicas para cada micro-organismo, podendo alguns meios de cultura conter mais de 30 ingredientes distintos, segundo dado fornecido pela empresa. Aubritet al. (2015) afirmaram a necessidade de estudos para otimizar tanto o crescimento celular quanto o viral, pois esses nem sempre exigiriam as mesmas condições para a produção ótima. Hiss (2001) e a empresa Sanofi Pasteur (2012b) apontaram ainda para a importância devários parâmetros a serem considerados durante a produção, de maneira que a reprodutibilidade do processo seja finamente monitorada através de informações sobre $\mathrm{pH}$, curvas de crescimento (através de densidade ótica), análise de oxigênio dissolvido, entre outras análises.

A respeito da necessidade do controle do processo, o trabalho de Buckland (2005) 
demonstrou que na produção das vacinas, devido às dificuldades de análise para confirmação da composição, é a própria forma de produção que determina o produto. Isso explicaria a burocracia junto aos órgãos reguladores e o cuidado para qualquer tipo de mudança no processo, pois poderiam ser exigidos novos testes clínicos para que fosse comprovado que a vacina produzida sob novas condições teria a mesma eficácia que a produzida anteriormente.

Devido a essas dificuldades reportadas por Buckland (2005), foram desenvolvidas inovações a fim de que os projetos das instalações se tornassem mais flexíveis. Josefsberg e Buckland (2012) reportaram, nesse caso, a utilização da tecnologia descartável ou de utilização única. Segundo os autores, o uso de biorreatores de uso único (SUBsSingle Use Biorreactors) permite não só menor capital de investimento para as instalações, mas também tempos de troca mais curtos, maior produtividade, menor risco de contaminação e menos rejeitos. Os autores citam também outros equipamentos de uso único utilizados no processo, como kits de purificação. Aubritet al. (2015) também considerou as vantagens de serem usados equipamentos desse tipo, apesar da necessidade de investimentos iniciais.

Dando seguimento à descrição do processo realizada pela empresa Sanofi Pasteur (2012b), a etapa seguinte ao cultivo seria a purificação, na qualimpurezas e traços do meio de cultura são removidos. A empresa afirmou que o tempo de cultivo das células varia na faixa de dois a três meses, dependendo do tipo de vacina a ser produzido. Aempresa Boehringer Ingelheim Vetmedica (2015) descreve que essa etapa pode ser executada a partir da utilização de filtros de membranas, filtros prensas ou através de centrifugação, dependendo do produto.

Josefsberge Buckland (2012) destacam a utilização de polietileno glicol e a extração utilizando solventes como procedimentos essenciais durante a etapa de purificação, além dos processos físicos já citados. A purificação da vacina contra a hepatite $\mathrm{A}$, denominada vacina VAQTA, da Merck, é realizada a partir de cromatografia e precipitação dos vírus pela adição de polietileno glicol, com posterior extração líquido-líquido com clorofórmio, a fim de que os vírus viáveis fiquem na fase aquosa e as proteínas contaminantes, desnaturadas irreversivelmente, fiquem na fase orgânica.

Josefsberge Buckland (2012) alertaram para a sensibilidade do processo de separação. A alta exigência de pureza e reprodutibilidade da vacina contra a hepatite A, nesse caso, teria sido conseguida por uma etapa adicional de adição de nucleases. Essas enzimas foram responsáveis pela quebra de ácidos nucleicos que passavam pela purificação via membrana 
e coprecipitavam quando havia adição de polietileno glicol, resultando em problemas de purificação e rendimento. Essa nova etapa, seguida do uso de uma coluna de cromatografia aniônica (AEX- Anion Exchange Chromatography) teria proporcionado otimização dos resultados. Hennessey Jr.et al. (1999) comprovaram a eficácia desse método de purificação defendidos por Hagen et al. (1996) e descritos por Josefsberge Buckland (2012), utilizando técnicas de análise mais avançadas.

Dentre as tecnologias de uso único para a purificação reportadas por Josefsberg e Buckland (2012) foram citadospelos autores os cartuchos de adsorção descartáveis, usados na remoção de DNA, proteínas residuais das células hospedeiras ou para a remoção de vírus, das empresas Sartorius Stedim e Natrix (Burlington, Canadá), as membranas da empresa Pall Corporation (Port Washington, Nova Iorque), com finalidade semelhante e colunas cromatográficas das empresas GE Healthcare (Little Chalfont, Reino Unido), Millipore (Billerica, Massachusetts), BioFlash Partners (Worcester, Massachusetts) e Tarpon Biosystems (Marlborough, Massachusetts).

Aubritet al. (2015) destacaram que justamente a etapa de purificação seria a responsável pela maior parte dos custos na produção das vacinas. Segundo os autores, as altas exigências dos organismos reguladores são responsáveis por uma perda de boa parte dos antígenos durante essa etapa. Os autores afirmaram, assim, que os estudos referentes à purificação das vacinas adquiriram grande relevância dentro da tecnologia de produção de vacinas.

Inativação, formulação e finalização :

A empresa Sanofi Pasteur (2012b) descreveu que logo após a purificação pode-se proceder a inativação. São adicionados, então, estabilizantes ou conservantes em baixas dosagens, além de adjuvantes para alguns casos. A etapa seguinte consiste em preencher seringas ou vials com a vacina. Segundo Rappuoli (2006), essa última etapadeve ser realizada de maneira que os vials ou seringas estéreis sejam preenchidos com a vacina também estéril. É reafirmada ainda, segundo o mesmo autor, a necessidade de que também o ambiente mantenha condições estéreis durante esse procedimento.

Jofesberg e Buckland

reportaram que normalmente nenhum conservante é utilizado em vials ou seringas contendo vacinas de dose única devido a preocupação com os possíveis efeitos adversos do uso de timerosal, conservante a base de mercúrio, apesar dos efeitos tóxicosdessa substância serem controversos (KHANDKEet al., 2011). Van'tVeen(2001) cita, por exemplo, o fato de que mulheres em idade fértil não deveriam receber timerosal devido aos riscos para a formação do cérebro do feto durante seu desenvolvimento. Assim, 
segundo Khandkeet al. (2011), para o caso de vacinas de múltiplas doses, têm sido envidados esforços para novos conservantes, como o estudo reportado pelos próprios autores no uso do 2-fenoxietanol.

Segundo Schatzmayr (2003), Rappuoli (2006) e a empresa Sanofi Pasteur (2012b) pode-se definir os adjuvantes, adicionados nos casos mostrados no Quadro 1, como substâncias que podem ser adicionadas à formulação das vacinase que auxiliam na manutenção da potência davacina e mesmo na resposta imunológica do organismo, podendo ainda diminuir a quantidade de antígenos necessários por dose. Schatzmayr (2003) e JosefsbergeBuckland (2012) descrevem que os sais de alumínio (hidróxido ou fosfato) podem ser utilizados como adjuvantes para a administração em seres humanos. Segundo o primeiro autor, existe uma união de caráter iônico entreos sais de alumínio e as proteínas da vacina, de modo que essas proteínas são liberadas paulatinamente no organismo, aumentando a resposta imunológica.

De acordo com a empresa Sanofi Pasteur (2012b) algumas vacinas não são estáveis na forma líquida, sendo necessária, nesses casos, uma etapa adicional na qual a água é removida através do congelamento com nitrogênio líquido e ação do vácuo (liofilização). Obtém-se, assim, um pó, ao qual será empregado um diluente apropriado para o momento da aplicação. Amorijet al. (2007) destacou a necessidade de adicionar-se agentes de proteção durante essa etapa, geralmente carboidratos (como trealose, inulina e dextrano), uma vez que as propriedade imunogênicas das vacinas poderiam ser perdidas devido a alterações na conformação das proteínas. Segundo os autores, os carboidratos contribuiriam para a formação de uma matriz vítrea que impediria a degradação das proteínas devido à redução de fatores como difusão emobilidade.

Chen et al. (2010), por sua vez, reportaram a existência de esforços a fim de garantir a estabilidade das vacinas mesmo à temperatura ambiente, utilizando, por exemplo, técnicas de spray-drying. Isso seria devido a dificuldade de manutenção das redes de frio. Os autores reportaram um estudo em que uma formulação da vacina contra a hepatite $\mathrm{B}$, submetida à técnica de spray-drying, mostrou-se estável por cerca de 24 meses a $37{ }^{\circ} \mathrm{C}$. Indicaram, no entanto, a necessidade de que a técnica também pudesse ser aplicada no caso das vacinas vivas, que são geralmente as que são submetidas ao processo de liofilização.

A empresa Sanofi Pasteur (2012b) relatou, para a finalização do processo, o uso de inspeção visual, além do auxílio de computadores com a mesma finalidade. Qualquer embalagem fora dos padrões, segundo a empresa, é descartada. Para garantir a potência das vacinas, salientou a empresa, 
deve-se tomar cuidado com a temperatura de armazenamento, e mesmo com a exposição à luz. JosefsbergeBuckland (2012) alertaram para o fato de que um empacotamento mais eficiente nessa etapa favoreceria a diminuição do espaço ocupado pelas vacinas nas câmaras de frio, beneficiando os países em desenvolvimento, que têm dificuldades de manter uma rede de frio, além de diminuir os gastos dos países desenvolvidos.

\subsection{O Cultivo Celular}

Kretzmer (2002) atestou que os estudos referentes às condições de desenvolvimento das células que serão infectadas com os vírus são feitos inicialmente em escala laboratorial, utilizando-se pequenos erlenmeyerse aumentando-se aos poucos a escala. Segundo o autor, o cultivo das células ocorreria apenas com o objetivo de promover a infecção viral, de modo que haveria a vantagem de não ser necessário mantê-las viáveis por um longo tempo durante a produção. Hiss (2001), Kretzmer (2002) e Astleyet al. (2007) apresentaram as opções de realizar-se múltiplas culturas, como frascos rolantes ou monocamadas, ou a de realizar-se escalonamento para produção em reatores maiores, dependendo das condições encontradas. A primeira opção seria a mais cara e que demanda mais tempo, além de possuir um maior risco de contaminação, enquanto a segunda opção seria a mais atrativa economicamente, mas também a mais difícil.

De acordo com Kretzmer (2002), o uso de múltiplas unidades pode ser preferível quando são encontrados fatores como a sazonalidade na produção de alguns tipos de vacinas e a dificuldade de crescimento celular em condições de agitação, quando é exigido um suporte. Hiss (2001) mostrou que o uso de biorreatores com cultivo submerso de células permite uma maior homogeneização do meio e uma facilitação do controle do processo, viabilizando uma melhor reprodutibilidade e aumentando a produção. Como exemplos para o primeiro tipo de cultura Aubritet al. (2015) citaram Rotarix ${ }^{\circledR}$, $\operatorname{Varivax}^{\circledR}, \operatorname{Meruvax}^{\circledR}$.

Hiss (2001) e Kretzmer (2002) mencionaram que apesar do cultivo submerso ter trazido vantagens para a produção das vacinas virais, existem também complicações em sua implementação, como a dificuldade da manutenção das células em suspensão, além de nessa forma elas tenderem a não se multiplicar normalmente. Ambos os autores atestaram o uso de microcarreadores para contornar esse empecilho. Esses microcarreadores permaneceriam em suspensão, ao mesmo tempo que serviriam de suporte para as células. Kretzmer (2002), no entanto, afirmou que as células também podem ser adaptadas para crescer em 
suspensão, sendo essa uma opção preferível. Nesse caso, Aubritet al. (2015) enumeraram as linhagens MDCK, PER.C6 ${ }^{\circledR}, \quad$ EB66 ${ }^{\circledR}$ e AGE1.CR ${ }^{\circledR}$ como passíveis de serem usadas sem o uso de suporte. Segundo Astleyet al.(2007) a adição de Pluorônico F68 ao meio de cultura, por exemplo, mostrou ser um procedimento efetivo nessa adaptação, apesar dessa demandar muito tempo. O Pluorônico F68, de acordo com JosefsbergeBuckland (2012), é um polímero não-iônico capaz de reduzir os danos que o borbulhamento produz nas células. O Quadro 8 mostra alguns desafios para o cultivo das células.

Quadro 8- Alguns desafios para a engenharia nos métodos de cultivo celular com o uso de carreadores e de suspensão live.

\begin{tabular}{|l|l|l|}
\hline Tipo de cultivo & \multicolumn{1}{|c|}{ Descrição } & \multicolumn{1}{c|}{ Principais desafios } \\
\hline Carreadores & $\begin{array}{l}\text { As células necessitam de estar ancoradas, } \\
\text { crescendo em microcarreadores sólidos. } \\
\text { Necessidade de adaptação às tensões de } \\
\text { cisalhamento devido a agitação para que possa } \\
\text { haver fixação, maior fase lag e necessidade de } \\
\text { preparação dos microcarreadores (inchaço e } \\
\text { autoclavagem). }\end{array}$ \\
\hline Suspensão livre & $\begin{array}{l}\text { As células estão suspensas e crescem } \\
\text { processo é fácil, sendo uma tecnologia } \\
\text { robusta. Não há necessidade de fatores de } \\
\text { adesão. Os custos são mais baixos. }\end{array}$ & $\begin{array}{l}\text { Necessidade de maiores volumes e maior tempo } \\
\text { de retenção. }\end{array}$ \\
\hline
\end{tabular}

FONTE: Rappuoli (2006).

Kretzmer (2002) ressaltou que no processo de cultivo submerso feito em pequena escala a razão de superfície-volume de cultura é alta, tornando mais fácil a manutenção do nível de oxigênio no sobrenadante. Quando se usa um tanque agitado, no entanto, segundo o autor, essa razão é negligenciável, sendo necessário o desenvolvimento de equipamentos para suprir oxigênio tais como borrifadores, defletores e impelidores de baixo cisalhamento. De acordo com o autor estudos com biorreatores empregando células animais demonstraram ser muito difícil o crescimento de suspensões celulares em alguns tipos de reator tais como borrifador, coluna de bolhas ou airlift, pois esses exigem aditivos de proteção. Essas dificuldades seriam provenientes da interação das células com as bolhas formadas, o que poderia ser contornado com o uso de membranas, apesar do escalonamento nesse caso ser mais difícil. O Quadro 9 indica os aspectos físicos e biológicos a serem considerados no projeto de um reator de cultura celular. 
Quadro 9- Aspectos físicos e biológicos a serem considerados no desenho de um reator com cultura de célulasanimais.

\begin{tabular}{|c|c|}
\hline Aspectos Físicos & Aspectos biológicos \\
\hline $\begin{array}{l}\text { 1. Desempenho de transferência de massa. } \\
\text { 2. Fluxo na interface líquido-ar. } \\
\text { 3. Convecção mássica e mistura da fase líquida com o ar. } \\
\text { 4. Capacidade de dispersão do ar } \\
\text { 5. Consumo de energia (ou taxa média específica de } \\
\text { dissipação de energia , } \varepsilon_{\mathrm{T}} \mathrm{W} \mathrm{kg} \text { ). } \\
\text { 6. Variação nas taxas de dissipação de energia } \\
\text { específicas locais , } \varepsilon_{\mathrm{T}} \mathrm{W} \mathrm{kg}^{-1} \text { ). } \\
\text { 7. Transferência de calor. } \\
\text { 8. Suspensão dos microcarreadores (para células } \\
\text { suportadas). }\end{array}$ & $\begin{array}{l}\text { 1. Crescimento e produtividade. } \\
\text { 2. Nutrientes e outros aditivos, incluindo oxigênio. } \\
\text { 3. Produção de } \mathrm{CO}_{2} \text { e quociente de respiração. } \\
\text { 4. Sensibilidade ao } \mathrm{O}_{2} \text { e concentração de } \mathrm{CO}_{2} \text {. } \\
\text { 5. Faixa de pH e sensibilidade. } \\
\text { 6. Faixa de operação de temperatura. } \\
\text { 7. Sensibilidade das membranas celulares às forças } \\
\text { decisalhamento. }\end{array}$ \\
\hline
\end{tabular}

FONTE: Nienow (2006).

Segundo Nienow (2006), os biorreatores são operados basicamente em regime turbulento, sendo que as necessidades de transferência de calor são facilmente atendidas pelo uso de reatores encamisados. De acordo com o autor, as temperaturas típicas para biorreatores com células animais variam entre 36 e $38{ }^{\circ} \mathrm{C}$. Por fim, Nienowtambém comentou sobre as dificuldades de aeração encontradas nos reatores industriais devido à excessiva preocupação inicial com o efeito das tensões de cisalhamento sobre as membranas celulares. Estudos posteriores, segundo o autor, mostraram que elas não eram tão significativas quanto esperado inicialmente. Essa informação também é encontrada em Kretzmer (2002), que afirmou que o efeito do borbulhamento seria mais importante que o das tensões de cisalhamentos sobre as células.

Segundo Tapiaet al. (2016) existem poucos estudos tratando do cultivo celular em alta densidade (HCD- High CellDensity) ou em produção contínua para a fabricação de vacinas virais, a não ser aqueles restritos basicamente às condições laboratoriais. Os autores apresentaram alguns obstáculos que explicam a dificuldade para a implementaçãodesses processos, destacando dentre eles a falta de conhecimento sobre como os vírus se comportariam sob essas novas condições, considerando, por exemplo, a possibilidade de haverem mutações devido ao tempo de retenção distinto daquele de reatores convencionais. Segundo o autor, isso torna mais complexo o licenciamento dos processos junto aos órgãos reguladores. No entanto, Walther et al. (2015) estimaram, no caso da produção de proteínas, que o processo contínuo poderia reduzir os custos tanto de capital quanto operacionais quando comparados com processos em batelada, considerando, para isso, um período de dez anos. Os resultados das pesquisas, conforme Tapiaet al. (2016), mostraram ser promissores e, segundo eles, o uso de processos análogos 
aos já utilizados para a produção de proteínas recombinantes, como a batelada alimentada e perfusão à base de membranas/fibras ocas é interessante. A implementação de cultivos HCD usando estratégias batelada-alimentada ou perfusão, segundo eles, ofereceria a possibilidade de aumentar a produtividade das vacinas de 10 a 100 vezes em comparação com as culturas convencionais.

Tapiaet al. (2016) descreveram ainda que sistemas multiestágios de tanques agitados mostraram resultados interessantes a nível laboratorial. Devido à complexidade do processo, sistemas com três tanques ou mais, segundo os autores, dificilmente seriam implementados em larga escala. O uso de dois tanques, no entanto, sendo o primeiro tanque destinado ao crescimento celular e o segundo à infecção viral e à propagação dos vírus, pareceu ser uma boa opção. Mesmo para esse caso, o impacto da variação do tempo de retenção em relação ao reatores convencionais deveria ser avaliado para que as características imunogênicas das vacinas não sejam perdidas. Os autores concluíram, assim, que os cultivos com alta densidade celular e o uso de cascatas de tanques agitados são linhas mestras para o desenvolvimentos de novos processos industriais em termos de cultivo celular .

De acordo com Aubritet al. (2015) a implementação de processos contínuos traria a grande vantagem de integrar os processos de upstream e downstream não havendo, no entanto nenhum exemplo de processo industrial já empregando um sistema desse tipo. Aubritet al. (2015) enumeraram como outras vantagens do processo a diminuição do estresse celular, uma vez que os nutrientes seriam mantidos constantes e os metabólicos tóxicos seriam retirados, o aumento dos rendimentos celulares e a purificação direta, que traria uma melhor qualidade para o produto.

Como aplicação da tecnologia de uso único em biorreatores Josefsberg e Buckland (2012) citaram os exemplos da empresa GE, que fabrica WaveBioreactors ${ }^{\mathrm{TM}}$ em volumes superiores a $500 \mathrm{~L}$, usados no crescimento do inóculo, e das empresas Xcellerex, Thermo Scientific (Marlborough, MA) e Sartorius Stedim (Goettingen, Alemanha) na produção de tanques agitados com volumes de até 2000 L. De acordo com os autores os tanques agitados assim produzidos mostraram-se melhores em termos de transferência de massa que os WaveBioreactors ${ }^{\mathrm{TM}}$, além de possuírem opções melhoradas de agitação, aspersão e alimentação em comparação aos biorreatores de aço inoxidável. A necessidade de volumes maiores, segundo os autores, seria uma limitação desses biorreatores de tanque agitado do tipo SUBs. 


\section{ESTUdO DE CASO: PRODUÇÃO DE embriões estão vivos e bem vascularizados. VACINAS CONTRA O VÍRUS INFLUENZA}

\subsection{Infecção viral}

Para exemplificar a produção de vacinas será analisado o caso particular da vacina contra a influenza produzida pelo Instituto Butantan, que é o maior produtor de vacinas e soros da América Latina. A descrição é baseada na apresentação realizada pela Dra. CosueMiyaki no Simpósio sobre Produção de Vacinas, promovido pela Academia Brasileira de Ciências em 2013 e editada pela ASCOM (ABC, 2013).

\subsection{Recepção dos ovos}

A tecnologia empregada pelo Instituto Butantan para a produção dessas vacinas foi adquirida do Instituto Sanofi Pasteur, na França. São utilizados para esse fim ovos embrionados de galinhas da linhagem Hysexcriadas de modo controlado exclusivamente para produzirem ovos que serão usados na produção de vacinas. São adquiridos por dia entre 120 a 250 mil ovos contendo embriões de 10 a 11 dias.

Tomando-se cuidado com as condições assépticas do ambiente, os ovos são direcionados através de ventosas às bandejas do laboratório. A qualidade deles é então verificada por um ovoscópio automático. Uma amostragem vinda do caminhão, no entanto, é analisada manualmente a fim de se verificar se os ovos estão embrionados e se esses

Os ovos que passarem no teste são inoculados automaticamente com o vírus influenza. Uma pequena agulha perfura a casca do ovo, enquanto outra injeta no líquido alantóico o vírusinfluenza. Os ovos seguem então para a incubação, sendo que cada incubadora comporta cerca de 120 mil ovos. Seguida essa etapa, os ovos são colocados em câmaras frias para que haja a morte dos embriões e, pela retração dos vasos sanguíneos, os vírus que se multiplicaram possam ser liberados no líquido alantóico, que será recolhido, virando-se os ovos de cabeça para baixo após cortar-se o topo.

\subsection{Purificação}

Da inversão dos ovos são recolhidos cerca de $1500 \mathrm{~L}$ de líquido. Esse volume é filtrado, seguindo para a etapa de centrifugação a fim de que sejam eliminados outros componentes que possam ainda estar presentes como restos de membranas e hemácias. De 120 a 140 mil ovos obtém-se, ao final, cerca de apenas 100 litros de material concentrado. Esse volume é purificado ainda mais duas vezes, resultando em apenas 1 L. Essa etapa é a mais cara do 
processo, sendo que o concentrado contém um enorme número de doses de vacinas.

Uma vez purificado, o concentrado é tratado quimicamente, sendo diluído em um detergente que provocará a fragmentação dos vírus. Segue-se uma etapa de clarificação para retirar fragmentos maiores ou vírus inteiros que ainda persistiram. O material é então diafiltrado, removendo-se parte do detergente adicionado. Esse não é totalmente retirado por atuar como um adjuvante.

\subsection{Inativação}

A suspensão é então inativada com formol a fim de que os fragmentos virais percam a capacidade de se replicarem. Ocorre então outra filtração com vistas de promover a esterilização, sendo então realizada uma análise para verificar-se a qualidade final do produto. $\mathrm{O}$ material produzido é armazenado em câmaras frias até que seja unido a outros tipos de monovalentes (cada monovalente protege contra um tipo específico de vírus (MATTHEWS, 2006)), chegando-se finalmente à concentração pretendida. A vacina trivalente então produzida é envasada, após terem sido adicionadas também outras substâncias importantes para sua conservação. São realizados ainda outros procedimentos para o controle de qualidade, até que as vacinas assim produzidas sejam encaminhadas ao Ministério da Saúde.

\subsection{Considerações}

Apesar da maneira como a vacina contra a influenza é produzida atualmente pelo Instituto Butantan no Brasil, Rappuoli (2006), demonstrou algumas vantagens no uso de culturas celulares ao invés de ovos embrionados, dentre as quais podem ser destacadas as seguintes:

- A eliminação da necessidade de criar galinhas de maneira controlada;

- A conjunção e automação dos processos de upstream e downstream;

- A redução de contaminação potencial a partir de partículas viáveis e não viáveis;

- O start-up mais rápido para produção em larga- escala;

- A pureza inicial é maior;

Matthews (2006) também reconhece a tendência do uso de culturas celulares em substituição aos ovos embrionados no caso das vacinas contra a gripe. Os parâmetros de engenharia a serem considerados durante o processo, segundo Matthews (2006), continuariam a ser basicamente os mesmos.

\section{CONCLUSÃO}

A produção de vacinas é de elevada 
importância na prevenção das doenças. As novas formulações têm se beneficiado com os avanços da biologia molecular, no entanto permanecem dificuldades referentes ao desinteresse das indústrias farmacêuticas em uma produção mais acentuada. Isso deve-se aos altos investimentos exigidos, além dos altos riscos, somados à baixa representatividade de mercado. Os engenheiros de processos, trabalhando em equipes multidisciplinares, podem contribuir nesse campo projetando meios mais eficientes e eficazes de processo, nos quais os riscos sejam diminuídos e os lucros possam ser mantidos sem, no entanto, prejudicarem as pessoas mais pobres, garantindo que as questões de biossegurança e bioética sejam respeitadas. A produção contínua ou com células de alta densidade pareceu ser promissora e, se empregada, poderá tornar o processo mais atrativo. As novas alternativas de formulação que dispensem o uso de câmaras de frio também mostraram ser um importante passo na universalização do acesso às vacinas. Os aspectos éticos mostraram-se relevantes, exigindo dos pesquisadores comprometimento a fim de que sejam implementadas alternativas ao uso de linhagens celulares humanas derivadas de abortos provocados, parte essa que será discutida na segunda parte do artigo.

\section{REFERÊNCIAS}

ABC (Academia Brasileira de Ciência). Entenda como é produzida uma vacina. Disponível em: <www.abc.org.br/IMG/pdf/do c-4906>. Acessoem: 25 mai. 2016.

ALLISON, N.; TRANTER, H. S.From Vaccine Research to Manufacture: A Guide for the Researcher. In: ROBINSON, A.;HUDSON, M. J; CRANAGE, M. P. (ed.). Vaccine Protocols. 2nd.Totowa: Humana Press, 2010. p. 391-407.

AMORIJ,J-P.;MEULENAAR,J.;HINRICHS, W.L.J.;STEGMANN,T.;HUCKRIEDE,A.;CO ENEN,F.;FRIJLINK, H.W.Rational design of an influenza subunitvaccinepowder withsugarglass technology:Preventing conformational changes ofhaemagglutinin during freezing and freeze-drying. Vaccine, v.25, n. 35, p. 6447-6457, ago. 2007.

ANDRE, F. E.; BOOY, R.; BOCK, H. L.; CLEMENS, J.; DATTA, S. K.; JOHN, T. J.; LEE, B. W.; LOLEKHA, S.; PELTOLA, H.; RUFF, T.A.; SANTOSHAM, M.; SCHMITT, H. J. Vaccinationgreatly reduces disease, disability, death and inequityworldwide.

Bulletin of the World Health Organization, v.86, n.2, p.81-160, fev. 2008. Disponível em: $<$ http://www.who.int/bulletin/volumes/86/2/0 7-040089/en/>. Acesso em:4 jul. 2016.

ASTLEY, K.;NACIRI, M.;RACHER, A.;AL-RUBEAI, M.The role of $\mathrm{p} 21^{\text {cip } 1}$ in adaptation of $\mathrm{CHO}$ cells to suspension and protein-freeculture. Journal ofBiotechnology, v.130, p.282-290, jun. 2007.
AUBRIT,F.; PERUGI,F.;LÉON,A.; GUÉHENNEUX,F.; CHAMPION-ARNAUD,P.;LAHMAR,M.;SC HWAMBORN, K.;Cell substrates for the production of viral vaccines. Vaccine, v.33, n.44, p. 282-290, nov. 2015. 
BOEHRINGER INGELHEIM VETMEDICA.

YouTube. Vaccine Production Process at

BIVI.Vídeo

(12min15s).Disponívelem: $<$ https://www.youtube.co

$\mathrm{m} /$ watch? $\mathrm{v}=\mathrm{L} 8 \mathrm{gc} 7 \mathrm{nwbcDA}>$. Acessoem: 2 jun.

2016.

BUCKLAND, B.The process development challenge for a new vaccine.Nature Medicine

Supplement, v. 11, n. 4, p. S16-S19, abr. 2005.

\section{CENTERS FOR DISEASE CONTROL AND}

PREVENTION.List of Vaccines Used in

UnitedStates.Disponível em:

<http://www.cdc.gov/vaccines/vpd-vac/vaccines-list .htm>. Acessoem: 5 jul. 2016.

CHEN,D.;KAPRE,S.;GOEL,A.;SURESH,K.;BERI, S.; HICKLING,J.;

JENSEN,J.;LAL,M.;PREAUD,J.M.;LAFORCE,M.; KRISTENSEN,D. Thermostable formulations of a hepatitis $B$ vaccine and a meningitis $A$ polysaccharide conjugate vaccine produced by a spray drying method. Vaccine, v.28, n. 31, p.6447-6457,jul. 2010.

DUARTE, F. Epidemia do zika poderá acelerar 'ressurreição' do mercado global de vacinas.Disponível em:<http://www.bbc.com/ portuguese/noticias/2016/02/160203_zika_vacina_e conomia_fd>. Acessoem: 5 jun. 2016.

FRIERSON, J. G. The Yellow Fever Vaccine: A History. Yale Journal of Biology and Medicine, v. 83 (2), p.77-85, jun. 2010.

HENNESSEY JR., J. P.; OSWALD,C.B.;DONG, Z.;LEWIS, J. A.;SITRIN, R. D.Evaluation of the purity of a purified, inactivated hepatitis A vaccine (VAQTA $^{\mathrm{TM}}$ ). Vaccine,v.17, n. 22, p. 2830-2835, jul. 1999.

HISS, H. Produção de Vacinas. In: LIMA, U. deA.; AQUARONE, E.; BORZANI, W.; SCHIMIDELL, $\mathrm{W}$ (Coords.). Biotecnologia Industrial: Processos fermentativos e enzimáticos.Vol3.São Paulo: Edgard Blucher, 2001. 1 a reimpressão 2005.p.
307-346.

JOSEFSBERG,J. O.; BUCKLAND,B.

Vaccine Process Technology. Biotechnology and Bioengeneering, v.109, n.6, p.1443-1460, jun. 2012.

KHANDKE,L.;YANG,C.; KRYLOVA,K.; JANSEN,K. U.; RASHIDBAIGI, A.

Preservative of choice for $\operatorname{Prev}(\mathrm{e})$ nar $13^{\mathrm{TM}}$ in a multi-dose formulation. Vaccine, v.29, n. 41, p. 7144-7153, set. 2011.

KRETZMER, G. Industrial processes with animal cells. Applied Microbiology and Biotechnology, v.59, n.2, p. 135-142, jul.2002.

KREUZER, H.; MASSEY, A. Biology and Biotechnology: Science, Aplications, and n.s. United States: ASM Press, 2005.

MATTHEWS,J. T.Egg-Based Production of Influenza Vaccine: 30 Years of Commercial Experience. The Bridge, v.36, n.3, p. 17-24, outono 2006.

NCBC (The National Catholic Bioethics

Center).FAQ on the Use of

Vaccines.Disponívelem:

<http://www.ncbcenter.org/

resources/frequently-asked-questions/use-vacc ines/>. Acesso em: 5 jul. 2016.

NIENOW, A. W.Reactor engineering in large scale animal cell culture. Cytotechnology, v. 50, n. 1-3, p.9-33, jun. 2006.

NORRBY, E. Yellow fever and Max Theiler: the only Nobel Prize for a virus vaccine. The Journal of Experimental Medicine, v. 204, n. 12, p.2779-2784, nov. 2007. 
ORGANIZAÇÃO MUNDIAL DA SAÚDE (OMS). Vaccine

market.Disponívelem:<http://www.who.int/immuni zation/programmes_systems/procurement/market/gl obal_supply/en/>.Acessoem: 5jun. 2016.

PAILLET,C.;FORNO,G.; KRATJE, R.; ETCHEVERRIGARAY, M.Suspension-Vero cell cultures as a platform for viral vaccine production. Vaccine, v. 27, n. 46, p.6464-6467, out. 2009.

RAPPUOLI,R. Cell-Culture-Based Vaccine Production: Technological Options. The Bridge, v.36, n.3, p. 25-30, outono 2006.

SANOFI PASTEUR (a).YouTube.Making Vaccines - Part 1: The world of vaccines.Vídeo (6min05s). Disponível em:<https:// www.youtube.com/watch?v=-XG6-2AtJiE>. Acessoem: 2 jun. 2016.

(b).YouTube.Making

Vaccines - Part 2 : Vaccine Production. Vídeo (5min39s). Disponível

em:<https://www.youtube.com/watch?v=swmaJRKl 6EQ>. Acesso em: 2 jun. 2016.

SCHATZMAYR, H. G. Novas perspectivas em vacinas virais. História, Ciências, Saúde

-Manguinhos, Rio de Janeiro, RJ, v. 10

(suplemento 2), p. 655-669, 2003.
STEPHENS, P.Vaccine R\&D: Past

performance is no guide to the future. Vaccine, v. 32, n.19, p.2139-2142, abr. 2014.

STRUGNELL,R.; ZEPP,F.; CUNNINGHAM, A.; TANTAWICHIEN,T.Vaccine antigens. Perspectives in Vaccinology, v.1, p.61-88, ago. 2011.

TAPIA, F.; VÁZQUEZ-RAMÍREZ, D.; GENZEL, Y.; REICHL,U.. Bioreactors for high cell density and continuous multi-stage cultivations: options for process intensification in cell culture-based viral vaccine production. Applied MicrobiologyandBiotechnology, v. 100, n. 5, p.2121-2132, mar. 2016.

VAN'T VEEN, A. J.Vaccines without thiomersal: why so necessary, why so long coming?Drugs,v.61, p. 565-572, mai. 2001.

WALTHER, J.; GODAWAT, R.; HWANG, C.;ABE,Y.; SINCLAIR, A.;

KONSTANTINOV, K. The business impact ofan integrated continuousbiomanufacturing platform for recombinant protein production.Journal of Biotechnology, v. 213, p. 3-12, nov.2015. 